\title{
Attribution and Authorial (Dis) Endorsement in High- and Low-rated Undergraduate ESL Students' English Academic Persuasive Essays
}

\author{
Mark Brooke ${ }^{1}$ \\ ${ }^{1}$ Centre for English Language Communication, National University of Singapore, Singapore \\ Correspondence: Mark Brooke, Centre for English Language Communication, National University of Singapore, \\ Singapore. E-mail: elcmb@nus.edu.sg
}

Received: January 4, 2014

Accepted: January 16, 2014

Online Published: January 20, 2014

doi:10.5430/elr.v3n1p1

URL: http://dx.doi.org/10.5430/elr.v3n1p1

\begin{abstract}
This study draws on APPRAISAL theory (Martin and White, 2005), a linguistic system for interpersonal meaning, to investigate undergraduate students' engagement resources, with particular focus on attribution and authorial (dis) endorsement. An examination of the use of attribution and authorial (dis) endorsement between high and low-rated undergraduate EFL students' English argumentative essays was conducted. Both quantitative and qualitative data are presented. The research findings reveal that the high-rated essay writers used these evaluative resources much more successfully creating clear lines of contrastive positions. As these essays attained much higher scores, this indicates that academic readers value these resources highly. On the basis of the analysis, a discussion of some pedagogical implications ensues which highlights the need for academic English language instructors to devote more time on interpersonal meaning in the classroom.
\end{abstract}

Keywords: Heteroglossia, Engagement, Attribution, Authorial (Dis) Endorsement, Academic persuasive essay, Assimilated sources, Inserted sources, Source type

\section{Introduction}

\subsection{The argumentative persuasive essay genre}

Freadman's (1994) metaphor, equating rules of social etiquette with rules of genre, underlines the necessity for learners to understand the social norms of academic writing, in particular the discourse semantic and lexico-grammatical patterns construing a genre. For the novice writer, this can be a challenge without explicit instruction to demonstrate what is appropriate to write, and how to write it. Writing an academic text, such as the academic persuasive essay (APE) involves using a particular schematic design, and multiple lexico-grammatical patterns. For example, Lee (2008) presents the schema of this genre incorporating both an experiential (field) and an interpersonal (tenor) perspective. An introduction tends to begin with an 'identification' move. This has the dual function of simultaneously presenting the topic (realizing ideational meaning), and seeking the reader's attention (realizing interpersonal meaning). The APE is an example of a genre that requires great skill in developing reader/ writer interactions as interpersonal rational persuasion is its ultimate objective. A cogent (in contrast to non-cogent) academic argument is one that convinces effectively and this cannot be done by simple assert or disclaim. Commonly, the author, will appeal to Aristotelian logos (a reader's reason using logic and evidence) and Aristotelian ethos (invoking a reader's sentiments) to persuade or convince targeted individuals to believe a certain answer to a certain question or puzzle, while at the same time establishing Aristotelian credos, or a credible, authoritarian voice. This social event is governed by a multitude of writing conventions concerning the production and presentation of a text.

\subsection{Appraisal and the resources of intersubjective stance}

Applying dialogistic effects strategically to seek a reader's attention and inviting the reader to evaluate evidence and assessments is a considerable writing task and contributes to the construction of a successful interactive text, building solidarity between writer and reader, and this falls within the boundaries of 'interpersonal meaning' (Halliday, 1994). As Duszak states, 'academic discourse may not be insightfully studied with a disregard for a whole array of interpersonal meanings' (as cited in Wu, 2007: 255). Over the last decade, much work has gone into understanding how authors use linguistic resources to convey and involve their readers in personal assessments and opinions (Hood, 2004; Martin and White, 2005; Rothery \& Stenglin, 2000; White 1998, 2000, 2002). A writer will use differing levels of epistemic modality, expressing degrees of certainty towards a proposition, and this is a strategy adopted for 
construing stance, or to move from more closed positions to more open ones (more or less solidarity with readers). An 'assert': the work is excellent; or a 'disclaim': the evidence is insubstantial are closed moves; while the acknowledgment of potentially different views using modality (e.g., London seems to be a multicultural city) is comparatively open, because the writer demonstrates a willingness to acknowledge opinion from her reader. This demonstrates that there is an axis of variation in rhetorical functionality running from 'dialogically expansive' to 'dialogically contractive' (Martin and White, 2005; White 1998, 2000, 2002). Martin (2000) refers to this phenomenon in academic text as 'dialogistic alternatives' (Martin, 2000: 90-100), which is informed by Bakhtin's (1981, 1986a, 1986b) dialogism and heteroglossia under which all communication is 'dialogic' in nature because it refers to what has been communicated before, and simultaneously anticipates the responses of actual readers. Heteroglossia (multiple voices) comprise aspects of a language that are extra-linguistic such as evaluation, perspective, and ideological positioning giving additional meaning to words, beyond their strict literary definitions. This is common to all languages. Thus, the engagement system is said to simultaneously construe proposition (informational values) and proposal (interactional values). Proposal is equal to, if not at times, more important than proposition. As Voloshinov (1995: 139) states:

'The actual reality of language-speech is not the abstract system of linguistic forms, not the isolated monologic utterance, and not the psychological act of its implementation, but the social event of verbal interaction implemented in an utterance or utterances.'

Terms such as 'Engagement' (Martin and White 2005), Sentiment Analysis (Das and Chen, 2001), Opinion Mining (e.g., Dini and Mazzini 2002), 'Evaluation' (Hunston and Thompson, 2000), 'Hedging' (Hyland, 1996a, b. 2002), and 'Stance' (Biber, 2006) have been used to present qualitative and quantitative investigations in this field, in both written and spoken discourse, relying on single text or much larger corpus analyses for methodological approaches. Martin and White, 2005: 36) state:

'Engagement is concerned with the ways in which resources such as projection, modality, polarity, concession and various comment adverbials position the speaker/writer with respect to the value position being advanced and with respect to potential responses to that value position - by quoting or reporting, acknowledging a possibility, denying, countering, affirming and so on.'

Conveying stance and projecting evaluations, through the use of hedging, has been researched in ESL, in particular, by Hyland (1996a, b), who demonstrates that tentativeness in academic research articles can be conveyed through content-oriented hedges, which can simultaneously construe both the accuracy of a proposition and a writer's commitment to it. Several lexico-grammatical features performing communicative functions in this field are presented by Biber (2006), along with Thompson \& Ye (1991), and Hyland (2002), such as reporting verbs categorized as 'factive' (e.g., prove), whereby the writer presents an author as presenting true information or a correct opinion; 'counter-factive' (e.g., misuse), the author is presented as offering false information or an incorrect opinion; and 'non-factive' (e.g., advance), the writer gives no clear signal as to her attitude towards the author's information or opinion. Biber (2006) also identifies stance complement clauses in the form of stance noun + that-clauses and stance noun + to-clauses (e.g., the assumption that...; and the failure to recognize...); and stance clauses controlled by adjectives (e.g., It is unlikely that...); as well as stance clauses controlled by nouns (e.g., the hypothesis that....). These are just part of the rich variety of linguistic resources offered to writers in English to interact with a reader and work within the boundaries of the open/closed continuum.

\subsection{Attribution and authorial (dis) endorsement}

The aspects of engagement that this paper examines in ESL students are attribution and authorial (dis) endorsement, similar to the work reported above by Biber (2006), Thompson \& Ye (1991), and Hyland (2002). Attribution is the strategy of representing a 'non-factive' proposition as grounded in the subjecthood of an external voice, or significant other i.e., $X$ (author) said... Authorial (dis) endorsement is the ability to adopt a stance in relation to the presentation and evaluation of appropriate academic sources to support argumentation i.e., $X$ (author) claims that...; thus, applying 'factive' or 'counter-factive' lexico-grammatical features. An author, who merely reflects and produces propositions, without reporting the arguments or evidence of other respected academics in the field, lacks authoritative voice in written academic discourse, and cannot produce a high-level of persuasion. The same may be said for an author who solely refers to others' arguments to illustrate a point without positioning herself strategically in relation to these. The system academic writers can use to align themselves to other authors' ideas and arguments is brought about when a writer selects a direct citation or assimilates (paraphrases) a part of a text and embeds it into the paper to acknowledge that information from that source is salient to her communicative goals. Through writers' dynamic management of other voices in discourse in this way, they are able to convey different dialogic alternatives. 
They may, amongst other types of authorial positioning, appear to their readers as cautious, conciliatory, engaged or authoritative.

Attribution is the most basic evaluative stance (White, 2003) because the referent is given 'implied relevance' by merely choosing and citing the source. This is further extended by indicating whether it is 'endorsed' or 'disendorsed', to indicate the level of agreement or disagreement with the proposition. An endorsed utterance is commonly presented as one which is persuasive or reliable e.g., "Lenin convincingly demonstrated that small farms survive only by squandering the farmers' personal strength and the land's productive strength". Here the writer simultaneously cites Lenin's argument and indicates her alignment with it 'convincingly demonstrated'. In contrast, using a disendorsed utterance, distance is created between the writer and the referent, indicating a reluctance to align e.g., "Thatcher claimed only those who worked hard and pulled themselves up by the bootstraps should expect a good standard of living. " http://nursingclio.org/2013/04/11/when-i-remember-margaret-thatcher-i-remember/.

As already noted, a choice the writer must make with regard to attribution and authorial (dis) endorsement, is whether the source is used as a paraphrase (assimilated) or a direct citation (inserted). Both methods are common. However, on occasion, assimilated (dis) endorsement can be ambiguous:

'That was Tom's weakness it was demonstrated, many critics would later point out, in the length of his novels.'

In this example, taken from the Brown corpus

(http://conc.lextutor.ca/concordancers/show_context.pl?item=critics\&start=2919185\&this_corp=Brown_strip.txt\&ga ps =no_gaps\&sort_type=left\&search_type=equals\&lingo=English), it is difficult to know whether the author is endorsing the criticism or not. If the author therefore selects indirect speech of this nature, the distance between her and the external voice is lessened. It is thus essential to use this resource unambiguously to convey stance effectively. In contrast, use of direct, inserted citation does not tend to do this as these references immediately distance the author from the source. Authorial endorsement or disendorsement of this nature is typically realized through the use of the following resources: evaluative adverbs (e.g., convincingly), and factive/ counter-factive reporting verbs (prove, claim, suggest); epistemic modal verbs (ought to, should, may, might); passive constructions employing factive/ counter-factive reporting verbs (is clearly supported by); epistemic and evaluative adjectives (possible, probable. true); epistemic and evaluative nouns (likelihood, possibility, potential, proof); and concessive clauses (although, while).

Finally, source specification is another element in this area. Source selection can convey a writer's position with regards to her source (apart from SFL theorists, see Bernstein, 1971; Bourdieu, 1986; van Leewen, 2000). To refer to an identified source, employing a personalised resource is to engage concretely with it e.g., 'Smith (2010), the head of the research team, compellingly stated'. In contrast, 'the head of the research team compellingly stated' (Smith, 2010) increases distance. Similarly, using generic, unnamed sources tends to create distance by seeking universality e.g., 'People believe that Sachin Tendulkar was one of the best batsmen in Indian cricket' rather than 'Indians believe that Sachin Tendulkar was one of the best batsmen in Indian cricket. 'Here, it could be argued that the more specific 'many Indians' is less generalized and thus suppresses the claim by reducing its status. The following table reveals the different appraisal resources construing attribution and authorial (dis) endorsement for this paper's findings:

Table 1. Appraisal resources construing attribution and authorial (dis) endorsement

\begin{tabular}{|c|c|c|}
\hline $\begin{array}{l}\text { Attribution/ authorial (dis) } \\
\text { endorsement }\end{array}$ & Assimilated or inserted source & Source type \\
\hline $\begin{array}{l}\text { No endorsement (NE) } \\
\text { X states... }\end{array}$ & $\begin{array}{l}\text { Assimilated (AS): That was Tom's } \\
\text { weakness it was demonstrated, many } \\
\text { critics would later point out, in the } \\
\text { length of his novels.' }\end{array}$ & $\begin{array}{l}\text { Identified (IS): Mr Bryon, the } \\
\text { head of the research team, } \\
\text { compellingly stated... }\end{array}$ \\
\hline $\begin{array}{l}\text { Endorsed }(\mathrm{E}) \\
\text { X demonstrates... } \\
\text { Strongly endorsed (SE): } \\
\text { X convincingly demonstrates... }\end{array}$ & $\begin{array}{l}\text { Inserted (IS): "Well done is better } \\
\text { than well said," averred Ben } \\
\text { Franklin. }\end{array}$ & $\begin{array}{l}\text { Non-identified (NIS): The head } \\
\text { of the research team } \\
\text { compellingly stated... }\end{array}$ \\
\hline $\begin{array}{l}\text { Disendorsed (D) } \\
\text { X claims... } \\
\text { Strongly disendorsed (SD): } \\
\text { X wrongly propounds... }\end{array}$ & None & None \\
\hline
\end{tabular}




\section{The study}

The study aims to examine the interactive quality of high and low ranking scripts in the context of the academic persuasive essay using contrastive data to represent attribution and authorial (dis) endorsement, already established as parts of the appraisal framework. The purpose of the study is thus to further develop knowledge of this rhetorical genre, and to inform the teaching of English for academic purposes in L2 settings. Through the act of teaching an academic persuasive writing course, it became apparent to this author that low level scorers might require more input and training on how to use these linguistic resources. The research questions are as follows:

-What are some of the lexico-grammatical resources used by high and low scoring APEs to convey attribution and authorial (dis) endorsement?

.To what extent do high and low scoring papers differ in their use of these linguistic resources?

For the purposes of this study, the data set comprises three papers from ESL university first year undergraduate students receiving an A- (highest score), two with a B-, and one, a C+ (lowest scores). The only criteria for this selection were the grades that students received from their course tutor. The assignments were then double marked by two other lecturers, blind to the focus of this research, who applied a generic rating rubric for academic persuasive essays at a leading Asian Centre for English Language instruction to provide inter-rater reliability. This rubric focuses on holistic descriptors rather than more discrete items, for example, 'paper shows conceptual originality' or 'a mastery of the rhetorical principles' of the genre. There is no direct reference to 'attribution' or 'authorial (dis) endorsement. Thus, in addition to being unaware that the research was being undertaken, the markers were not consciously reflecting on the abilities of these ESL writers to use this particular linguistic resource when marking. The papers were selectively compared to offer both a quantitative and qualitative analysis of the linguistic resources under examination. The results of this research may be used as part of the current investigations into ESL students' linguistic resources and how these might be assessed for writing tasks of this nature.

Students are first year undergraduate ESL students in a high-ranking South-East Asian university, aged 18 to 21. These students are from a variety of faculties. The course is one of several within a faculty of writing, which seeks to develop students' linguistic capabilities and academic persuasive essay writing skills in English by offering different topics to explore both languages for specific purposes and rhetorical writing strategies. This particular module was entitled 'Sport and Competition'. The course's purpose is to provide a sociological analysis of sport as a cultural global phenomenon, with a particular focus, as the title suggests, on the tensions apparent in the emergence and growth of ultra-competitive, elite modern sports. The description of the course is the following:

"Is winning everything? Should participation or self-defining achievement be more valued? Is sport becoming too elitist? Does the obsession to win create the need for performance-enhancing drugs? Should we legalize doping or tighten control measures? Should we change the nature of professional competitive sport?"

The course analyzes sport as a cultural phenomenon in society. It has sociological underpinnings (Merton's ((1957)) strain theory and Durkheim's (1858-1917)) work on 'deviance') and also leans heavily on cultural studies (Gramsci's ((1982)) hegemony theory). A core set of twelve scholarly primary research articles from journals emanating from the sociology of sport, sport ethics, sport science and sport medicine discourse communities were selected. The final writing task requires students to find and evaluate primary and secondary source material to construct a researchable topic which presents debatable tensions. They are then expected to develop a suitable thesis with appropriate contestable elements for a genre of this ilk and compose a 1500 word paper. Sub skills such as APA and MLA in-text and out-of-text referencing in addition to portraying stance through authorial (dis) endorsement were covered in the teaching syllabus.

\section{Results of textual integration from the contrastive analysis}

A quantitative analysis of the propositions in the 1500-word essays was conducted to analyse the nature of attribution authorial (dis) endorsement in three high- and three low-scoring papers. 
Table 2. Number of instances of attribution

\begin{tabular}{lcc}
\hline Attribution & Number & Number \\
\hline & High scoring & Low scoring \\
No endorsement & 30 & 11 \\
Endorsement & 22 & 3 \\
Strong endorsement & 2 & 0 \\
Disendorsement & 2 & 1 \\
Strong Disendorsement & 0 & 0 \\
Total & 56 & 15 \\
\hline
\end{tabular}

One main distinction arises in the number of sources used to provide evidence and argumentation. It can be observed that a great deal more of these intertextual resources were used by the high scoring authors. A second difference in the papers is the degree of endorsement that was given to sources. While $39 \%$ of attribution was endorsed by the high scoring writers, lower scoring writers only endorsed $20 \%$ of the time. In addition, lower scoring authors did not attempt to strongly endorse. High scorers did strongly endorse but this was rare. The examples of strong endorsement, from the high scoring papers, follow. The first is an adverb + adjective + noun combination:

Example 1.

However many studies have subsequently provided highly cogent arguments as to why doping is in fact not against the spirit of sport (Savulescu, Davidson).

The second is a verb + preposition + noun combination:

Example 2.

When PEDs are prohibited, the athlete will be more tempted to obtain PEDs which are undetectable and accordingly, unavailable for safety testing. This scoffs of irony because it is counter-productive in promoting health as a value in the spirit of sport (Davidson).

In the following two sections, the two results pertaining to the predominant attribution strategies (assimilated and inserted text) are presented.

\subsection{Assimilated sources}

Table 3. Number of assimilated sources

\begin{tabular}{ll}
\hline Highest score papers & Lowest score papers \\
\hline 43 & 9
\end{tabular}

Quantitatively, both high scoring and low-scoring papers incorporated this resource with much the same vigour: 77\% of significant author integration of this ilk for high scorers; and $75 \%$ for low scorers. However, there was a significant difference in the quality between high and low scoring papers with regard to the use of assimilated sources. An example of a projecting clause, used with a non-factive reporting verb to introduce the author's proposition, from a high scorer is offered below.

Example 1.

Côté (1999) suggests that parents play a leadership role in child athletes' lives, and progress to a supporter role in adolescence.

This strategy, as expected, was very common among both sets of writers. However, where the high scorers showed no signs of difficulty with this resource, it was found that lower scorers occasionally made errors.

Example 2.

In "The Handbook of Social Psychology" (1998), studies by Gardner Lindzey et al. reveals that people's behavior towards one another can have a tremendous impact to one's thoughts, feelings and behaviors.

In this case, the student has incorrectly referred to the source type indicating that 'studies' is singular rather than plural with the wrong inflection 'reveals'. Perhaps to accommodate for the difficulty of this attribution strategy, low 
scoring papers tended to paraphrase and then add in the source at the end of the utterance, rather than projecting and evaluating, as below.

Example 3.

The more bureaucratization, extrinsic rewards and winning grow, the more each promotes the other (Crone, 1999).

Of the nine assimilated sources in the three low-scoring papers, six of them attributed the source in end position as above.

Reporting verbs used by high scoring papers were predominantly non-factive: found; suggest; report; posit; argue; note; ascertain; consider; reveal; emphasize. Although there were also factive reporting verbs: demonstrate, identify, prove, substantiate, assume; assert; and counter-factive reporting verbs: disregard, misuse. Low scoring papers also predominantly contained non-factive reporting verbs: believe; note; state; argue; show but also some factive reporting verbs: demonstrate, prove. Thus, high scoring papers demonstrated a more diverse set of reporting verbs, a higher use of factive verbs and were the only group that used counter-factive verbs. Another difference was observed in the complexity of the assimilated source. High scoring papers were able to manipulate this resource quite effectively using cleft structures along with projecting clauses containing adverbs for graduation and evaluative adjectives.

Example 4.

It is well established by leading experts Weising and Savulescu (Savulescu et al., 2004; Weising, 2011) that surpassing one's biological limitations is not just possible, but entirely feasible.

In comparison, none of the lower scorers attempted this combination. High scoring papers commonly presented propositions by integrating multiple sources at the end of assimilated text.

Example 5.

Burnout has been linked to parental criticism and high expectations (Gould, Tuffey, Udry, \& Loehr, 1996a, 1996b; Weirsma, 2000; Baker \& Robertson-Wilson, 2003).

In comparison, this phenomenon occurred in none of the low scoring papers. Finally, below is an example of how disendorsement was conveyed using both assimilation and insertion by a high scoring writer. This was introduced using an indefinite pronoun plus an evaluative adverb and a non-factive reporting verb.

Example 6.

Some have unconvincingly argued that doping is against the "spirit of sport" (Wiesing) and this is why we censure athletes for doping.

\subsection{Inserted sources}

Table 4. Number of inserted sources

\begin{tabular}{ll}
\hline Highest score papers & Lowest score papers \\
\hline 13 & 6
\end{tabular}

As with assimilated sources, the lower ranking essays only inserted citations and then end-sourced these, as below.

Example 1.

When athletes suffer from asthma, high blood pressure or cardiac arrhythmia, sport places their bodies "under unique stress that increases the chances of a chronic or catastrophic harm" (Savulescu et al, 2004).

However, where the high scorers showed no signs of difficulty with this resource, it was found that lower scorers occasionally made errors. In the example below, the student uses a citation to begin and complete an entire sentence.

Example 2.

"Today, modern sports can be expensive. An individual's ability to purchase a team membership, season tickets, or travel to compete in a marathon will be determined by the amount of disposable income" (Daniel C. Funk, 2008). 
The meaning the author wishes to convey may be clear but this practice is an unorthodox and generally unaccepted one. In cases of inserted text like these for the high scoring papers, authors tended to introduce the source first with a projecting clause and then use a colon before inserting the citation as in the following case.

Example 3.

In 1776, Thomas Jefferson proclaimed: "All men are created equal" (U.S. Declaration of Independence).

As with the lower scorer's example above from Savulescu et al. (2004), there were also, although to a lesser degree, inserted citations acting as the writer's own voice in high scoring papers.

Example 4.

This domination exemplifies and naturalizes class conflict, and by extension, brings into context the conflict within the racial hierarchy. After all, "all historical struggles ... are in fact only the more or less clear expression of struggles of social classes" (Engels, 1885), highlighting the intimate relationship between class conflict and racial inequality.

Finally, with regard to inserted sources, high scoring papers commonly inserted single terms as direct textual integration for a particular salient concept, to indicate that it was essential to the meaning being communicated:

Example 5.

Doping is deviant because it is a form of "innovation", whereby people accept the general goal of high performance while at the same time reject institutionalized means to do so by taking drugs instead (Luschen 466).

\subsection{Source type}

Table 4. Number of source types

\begin{tabular}{llll}
\hline High scoring papers & Number & Low scoring papers & Number \\
\hline Identified source (IS) & 56 & Identified source (IS) & 13 \\
Non-identified (NIS): & 0 & Non-identified (NIS): & 2 \\
\hline
\end{tabular}

All three of the high scoring papers identified all sources, whether through direct or indirect textual insertion. However, in contrast, the low scoring papers contained occurrences of unidentified sourcing. Two examples from the three papers were identified.

Example 1.

Surveys of adults, undergraduates and high school students have also found that 60 percent agree with the statement: "Human nature being what it is, there will always be war." (Alfie Kohn, 1988)

Example 2.

Many methods and pieces of research have been conducted to understand the phenomenon and to combat this problem.

In the first example, it is not clear if the writer's reference to Alfie Kohn (1988) is in fact expressing attribution for the statement "Human nature being what it is, there will always be war." or the Surveys of adults, undergraduates and high school students. It appears that it refers to the statement, although it is supplied without a page reference. In the second example, the subject is completely unidentified.

The use of adverbial sourcing using an adjunct, where the manifestation is explicit, was common amongst both high and low scoring papers. Most common among high scorers was the use of 'as' both introducing a proposition or in mid-text position.

Example 1.

As Bailey (2006) notes, improved cognitive development is correlational and should be interpreted as developed under specific conditions.

Example 2.

The least we can ascertain is that there are definite differences in the anatomy and physiology of different racial groups, as Fukashiro et al. (2002) suggest, in a comparison of viscoelastic characteristics in musculature between Black and White athletes. 
Interestingly, the use of 'according to...' to introduce an author was only used in the lower scoring papers. Once, it was used in an unorthodox manner.

Example 3.

According to the paper, the autonomous motivation has a greater impact on individuals as it yields a better mental health and more effective performance on expressive activities which includes sports.

This researcher used the Brown and BNC (written) corpora and did not find any occurrence of 'according to the paper'. Amongst the high scoring papers, an example of self-reference was observed, which was not found in the low scoring papers.

Example 4.

This author suggests that the phenomenon may be explained using Gramsci's Hegemony Theory from a conflict theorist's perspective.

Finally, an example below demonstrates how indirect source integration was unsuccessfully mediated by the low scoring writers.

Example 5.

Similarly, many researchers, who have spent their lives working on the problem of aggression, have concluded that violence is like selfishness, which is in human nature (Alfie Kohn, 1988).

Here, the writer refers to a plural number of researchers, but only cites one reference for this. There were no errors of this ilk among the high scoring papers.

\section{Discussion}

With regard to the research questions posed, the results offer fairly clear patterns of difference in the use of attribution and (dis) endorsement strategies. While these differences do not account for the reasons why one paper scored higher than another, it is clear that these add to the evaluative quality of the argumentation. Attribution and authorial (dis) endorsement are part of the wider system of evaluation and are used to create dialogic space. As already noted in the introduction, this is an important element of academic writing, and a good grasp of this strategy appears to be important for successful APEs. These strategies are instrumental for the expression of evaluation, contributing to the writer/ reader relationship. Through the sources ESL writers choose, and their alignment with these, a great deal of the argumentation is relayed.

Extending Wu's (2007) findings on ESL students' overall usage of engagement resources, this study demonstrates that there is a significantly higher frequency of attribution and authorial (dis) endorsement in high rating papers in particular. The low-scoring papers exhibited a much higher proportion of facts and assertions, or monoglossic text; and even reported studies without grounded evidence, as in example 2 for source type. It is clear that an anecdotal style lacking in attribution is not recommended in this essay genre, as it diminishes a writer's credibility. Academic readers consider claims carefully, and if a claim is unsubstantiated, this will undermine its effectiveness.

From the findings, it is evident that high and low scoring papers differ significantly in the number of directly inserted citations given against assimilated sources. The high scoring papers directly inserted sources only $27 \%$ of the time whereas the low scoring papers did this $60 \%$ of the time. Thus assimilated sources accounted for $63 \%$ of the high-ranking papers' attributions, and only $40 \%$ of the low-ranking papers' attributions. This phenomenon may stem from the fact that paraphrasing, as a micro-strategy of the summary task, requires the use of higher order reading and writing skills; including identifying the crux of the message and condensing this into text while entirely maintaining the focus of the original: no manner of semantic distortion can be afforded in this linguistic enterprise. Given the difficulty of the academic texts being used for the assignment, it is possible that low scoring authors found this a difficult task, and thus chose to safeguard the meaning through direct citation. This demonstrates that in-class instruction in paraphrasing tasks is essential for lower level students. Equally, the lack of projecting clauses, containing reporting verbs, adverbs for graduation and/ or evaluative adjectives in low-ranking papers for assimilated sourcing might be due to a lower level of linguistic abilities. This also demonstrates that in-class instruction in these strategies might prove beneficial for lower level students. Finally, there were even some errors in the use of attribution in low-scoring papers, pointing to the fact that there is a need to ensure that all writers in the writing classroom are able to at least use the simplest forms of attribution and authorial (dis) endorsement. These observations point to the premise outlined by Lee (2008: 264): 
'A major proposed educational implication for pedagogy about teaching second language writing is thus to foreground the social interactive and pragmatic nature of an APE'.

\section{Conclusion}

The present study has demonstrated that there are substantial differences in the management of attribution and authorial (dis) endorsement between low and high-ranking APEs. There is therefore a high correlation between interpersonal meaning of this nature and the quality of an APE. These results reveal that an effective essay is one which is considered as multi-voiced in nature and which conveys its argumentation clearly via its evaluation of significant others from its academic field. External evidence of this nature is applied to engage the reader and construct an authoritative voice. Their ability to use this resource more successfully, reflects the high-ranking ESL students' developed awareness of audience, and academic prose conventions. At the same time, it demonstrates that novice ESL APE writers lack either this level of awareness or the linguistic skills to be able to use these strategies effectively. High-ranking papers differed quantitative and qualitative-wise in their usage compared to low-ranking papers.

Exploring the academic argument from an interpersonal perspective, particular with regard to attribution and authorial (dis) endorsement, is still in its early stages. To explore the development of writing ability more fully, teachers need to stress that in order to persuade and convince an audience, a writer's ability to deploy interpersonal resources is just as important as being coherent. Attribution and authorial (dis) endorsement are significant elements of interpersonal meaning, and essential to the construction of APEs. Thus, the learning of this should be implemented in tertiary APE writing courses. It is hoped that this research has helped to develop understanding of APE construction and what differentiates the successful ESL writer from the novice in its production.

\section{References}

Allison, D. (1995). Assertions and alternatives: Helping ESL undergraduates extend their choices in academic writing. Journal of Second Language Writing, 4(1), 1-15. http://dx.doi.org/10.1016/1060-3743(95)90020-9

Bakhtin, M. M. (1981). The Dialogic Imagination: Four Essays. In M. Holquist, ed., C. Emerson and M. Holquist, Trans., University of Texas Press, Austin.

Bakhtin, M.M. (1986a). Speech Genres and Other Late Essays. In C. Emerson \& M. Holquist eds., Vern Mcgee, Trans., University of Texas Press, Austin.

Bakhtin, M. M. \& Volosinov, V. N., (1986b). Marxism and the Philosophy of Language. Trans. L. Matejka and I.R. Titunik, Harvard University Press, Cambridge, Mass.

Baker, J., \& Robertson-Wilson, J. (2002). On the risks of early specialization in sport. Physical and Health Education Journal, 69(1), 4-8.

Bernstein, B. (1971). Class, Codes and Control Vol 1: theoretical studies towards sociology of language. London, Routledge and Kegan Paul.

Biber, D. \& Finegan, E. (1988). Adverbial stance types in English. Discourse Processes, 11(1), 1-34. http://dx.doi.org/10.1080/01638538809544689

Biber, D. \& Finegan, E. (1989). Styles of stance in English: lexical and grammatical marking of Evidentiality and affect. Text, 9(1), 93-124. http://dx.doi.org/10.1177/096394709900800302

Biber, D. (2006). University language: A corpus-based study of spoken and written registers. Amsterdam: John Benjamins. http://dx.doi.org/10.1075/scl.23

Bourdieu, P. (1986). 'The Forms of Capital', in Richardson, John G., ed., Handbook of Theory and Research for the Sociology of Education, New York: Greenwood.

Crone, J. A. (1999). “Toward a Theory of Sport”. Journal of Sport Behavior. 1(1), 321-330.

Das, S. \& Chen, M. (2001). Yahoo for Amazon: Extracting Market Sentiment from Stock Message Boards. Proceedings of the 8th Asia Pacific Finance Association Annual Conference. (APFA, 2001), Bangkok, Thailand, July. Pp. 22-25.

Dini L. \& Mazzini G. (2002). Opinion classification through information extraction. In Zanasi A., Brebbia C. A., Ebecken N. F. F. and Melli P., Eds., Data Mining III, 299_310. WIT Press. 
Duszak, A. (1997). Cross-cultural academic communication: A discourse-community view. In A. Duszak (Ed.). Cultures and styles of academic discourse (Pp. 11-39). New York: Mouton de Gruyter. http://dx.doi.org/10.1515/9783110821048.11

Durkheim, Emile. (1997). The Division of Labor in Society. Trans. Lewis A. Coser. New York: Free Press.

Engels, F. (1885). 'Preface to the Third German Edition', in Marx, K. (2003). The Class Struggles in France: From the February Revolution to the Paris Commune. Lorimer, D. eds. and trans. New South Wales: Resistance Books. Pp.95, 97

Freadman, A. (1994). Anyone for tennis? In A. Freedman and P. Medway (Eds.) Genre and the new rhetoric. London: Taylor and Francis. Pp. 43-66.

Funk, D., C. (2008). Consumer Behaviour in Sport and Events. Elsevier.

Gould, D., Udry, E., Tuffey, S., \& Loehr, J. (1996). Burnout in competitive junior tennis players: I. A quantitative psychological assessment. The Sport Psychologist, 10(1), 322-340.

Gould, D., Tuffey, S., Udry, E., \& Loehr, J. (1997). Burnout in competitive tennis players: II. A qualitative analysis. The Sport Psychologist, 10 (1), 341-366.

Gramsci, A. (1982). Selections from the Prison Books. Lawrence and Wishart. London.

Halliday, M. A. K. (1994). An Introduction of Functional Grammar, $2^{\text {nd }}$ ed. London: Arnold.

Hood, S. (2004). Appraising Research: Taking a stance in academic writing. Faculty of Education University of Technology, Sydney, January 2004. Unpublished PhD.

Hunston, S. \& Thompson, G. (eds.) (2000). Evaluation in text: authorial stance and the construction of discourse. Oxford: Oxford University Press.

Hyland, K. (1996a). Writing without conviction? Hedging in science research articles. Applied Linguistics, 17(1), 432-454.

Hyland, K. (1996b). Talking to the Academy; forms of hedging in science research articles. Written communication, 13(1), 251-281. http://dx.doi.org/10.1177/0741088396013002004

Hyland, K. (2002). Directives: Argument and engagement in academic writing. Applied Linguistics, 23(2), 215-239. http://dx.doi.org/10.1093/applin/23.2.215

Jordan, M. P. (2000) 'Some discourse patterns and signalling of the assessment - basis relation'. Amsterdam: John Benjamins Publishing Company.

Martin, J.R. (1995a). 'Interpersonal Meaning, Persuasion, and Public Discourse: Packing Semiotic Punch', Australian Journal of Linguistics, 15(1), 3-67. http://dx.doi.org/10.1080/07268609508599515

Kohn, A. (1986). No Contest: The Case Against Competition. Boston: Houghton Mifflin.

Lee, S. H. (2008a). An integrative framework for the analyses of argumentative/persuasive essays from an interpersonal perspective. Journal of Text and Talk, 28(2), 239-270. http://dx.doi.org/10.1515/TEXT.2008.011

Lindzey, G., Gilbert, D. T., Fiske, S. T. (1998). The handbook of social psychology. Boston: McGraw-Hill.

Luschen, G. (2006). "Doping In Sport as Deviant Behaviour and its Social Control." Coakley, J., \& Dunning, E. Handbook of Sports Studies. London: Sage, 2006. Pp. 461-476.

Martin, J.R. (1995b). 'Reading Positions/Positioning Readers: JUDGEMENT in English', Prospect: a Journal of Australian TESOL 10(2), 27-37.

Martin, J.R. (2000). 'Beyond Exchange: APPRAISAL Systems in English', in Evaluation in Text. Hunston, S. \& Thompson, G. (Eds), Oxford, Oxford University Press.

Martin, J.R. \& White, P.R.R. (2005). The Language of Evaluation, Appraisal in English. Palgrave Macmillan, London \& New York.

Merton, R. (1957). Social Theory and Social Structure. Free Press.

Rothery, J. \& Stenglin, M. (2000). 'Interpreting Literature: The Role of APPRAISAL', in Researching Language in Schools and Functional Linguistic Perspectives. Unsworth, L. (Ed.), London, Cassell

Savluesco, T., Foddy, B., \& Clayton, M. (2004). "Why we should allow performance enhancing drugs in sport." British Journal of Sports Medicine. 38(6), 666-670. http://dx.doi.org/10.1136/bjsm.2003.005249 
Thompson, G. \& Ye, Y. (1991). Evaluation in the Reporting Verbs Used in Academic papers. Applied Linguistics, 12(1), 365-382. http://dx.doi.org/10.1093/applin/12.4.365

van Leeuwen, T. (2000). 'Programmed heteroglossia, information technology', Education and Society, 1(1), 7-23.

Voloshinov, V.N. (1995). Marixism and the Philosophy of Language, Bakhtinian Thought - an Introductory Reader. S. Dentith, L. Matejka \& I.R. Titunik, (Trans), London, Routledge.

Weirsma, L. D. (2000). Risks and benefits of youth sport specialization. Paediatric exercise science, 12(1), 13-22.

Weising, U. (2011). "Should Performance-Enhancing Drugs in Sport be legalized under Medical Supervision?" Sports Medicine. 41(2), 167-76. http://dx.doi.org/10.2165/11537530-000000000-00000

White, P.R.R. (1998). 'Telling Media Tales: the News Story as Rhetoric'. Unpublished Ph.D Dissertation, University of Sydney, Sydney.

White, P.R.R. (2000). 'Dialogue and Inter-Subjectivity: Reinterpreting the Semantics of Modality and Hedging', in Working with Dialog, Coulthard, M., Cotterill, J., \& Rock, F. (eds), Neimeyer.

White, P.R.R. (2002). The language of attitude, arguability and interpersonal positioning. Retrieved June, 2002 from http://www.grammatics.com/appraisal/index.html

White, P.R.R. (2003). Beyond modality and hedging: A dialogic view of the language of intersubjective stance. Text, 23(2), 259-284. http://dx.doi.org/10.1515/text.2003.011

Wu, S., M. (2007). The use of engagement resources in high- and low-rated undergraduate geography essays. Journal of English for Academic Purposes, (6), 254-271. 